\title{
A FORMAÇÃO LEITORA NO ENSINO FUNDAMENTAL E MÉDIO DO CAp UERJ
}

\author{
Gregory Magalhães Costa * \\ Luiz Carlos Coelho de Oliveira**
}

\begin{abstract}
Resumo: Qual papel a escola vem desempenhando na formação leitora dos estudantes? Quais fatores incentivam a leitura? Como ela principia? Este artigo visa refletir tanto sobre estas questões quanto em relação ao perfil leitor dos educandos de Ensino Fundamental II e Médio do CAp UERJ a partir do levantamento de dados realizado por meio de produção textual, intitulada "autobiografia literária", de modo a coletar relatos espontâneos oriundos de um mínimo de coordenadas, que forneçam dados mais precisos e fidedignos. Pensando o papel de um Colégio de Aplicação na nossa sociedade atual por meio da perspectiva da luta de classes e dos aparelhos ideológicos de Estado, pretende-se fornecer um panorama geral da formação de leitores para refletir sobre a possibilidade da construção de uma educação mais crítica, criativa e democrática.
\end{abstract}

Palavras-chave: CAp UERJ. Formação leitora. Leitura crítica. Política pedagógica. Libertação.

Introdução

Recém-ingressos como professores Adjuntos do Instituto de Aplicação Fernando Rodrigues da Silveira (CAp UERJ), interessou-nos pesquisar o perfil leitor de seus estudantes dos segmentos Fundamental II e Médio. Esta pesquisa é importante para partir dos conhecimentos prévios dos educandos, como defende Paulo Freire, e para conhecer os atalhos e entraves a uma formação leitora crítica, democrática e cidadã no Rio de Janeiro do início do século XXI, permeado pela obsessão por mídias sociais, pelo genocídio negro nas favelas, pela, consequente, superficialidade de leitura do texto e do mundo, num país cada vez mais marcado pelos discursos de ódio e autoritários, muitas vezes de forma oficial e provindo dos maiores cargos eletivos e jurídicos do Brasil.

O objetivo central é entender quais textos e gêneros literários circulam entre os estudantes dos diversos anos escolares do CAp UERJ, além de seus hábitos leitores. O que ou quem os incentivou a começar a ler? Qual a primeira obra lida? Como ela influenciou seu hábito leitor e sua formação enquanto tal? Eles seguem se considerando leitores? Em que situação gostam de ler? Por que (não) gostam de ler? O que os afasta da leitura? Quais gêneros e obras preferidas por cada segmento? Procuraremos responder essas questões, buscando interpretar os dados coletados, visando elaborar propostas de intervenção que incentivem uma leitura crítica, criativa, embasada e consistente do mundo e da palavra a partir da reflexão sobre o papel da escola neste processo.

\footnotetext{
* Professor Adjunto do CAp UERJ, bacharel, licenciado, mestre em Literatura Comparada e doutor em Literatura Brasileira pela UFRJ. E-mail: gregorymagalhaescosta@gmail.com

** Professor adjunto do CAp UERJ. Licenciado em Letras pela PUC-Rio. Pela mesma universidade, obteve o título de mestre em Letras (Estudos Literários) e de doutor em Literatura e Cultura. Cursou parte do doutorado, com bolsa-sanduíche, na Universidad Nacional de Rosario (Argentina). E-mail: luizoelho@yahoo.com.br
} 
Pensar qual formação de leitores queremos incentivar é pensar qual país queremos construir. Qual contribuição a formação de leitores de um Colégio de Aplicação pode fornecer para a nossa sociedade, para o nosso país? Queremos formar estudantes alienados por mídias sociais e pela propaganda ostensiva ou cidadãos críticos, com consciência democrática, que sabem respeitar as diferenças, mas também se colocar como sujeitos na luta de classes que se processa na escola e em toda a sociedade? Nossa formação leitora tem atingido esses objetivos? O que fazer para aprimorá-la no sentido de tangenciar cada vez mais os propósitos apresentados?

Entendemos que a resposta a essas questões pode fornecer uma contribuição à nossa sociedade, por meio da reflexão sobre a formação leitora praticada e a ser praticada em nossa instituição a partir de dados sólidos provindos dos próprios estudantes e analisados de forma profícua e científica em uma interpretação crítica classista e libertária.

\section{Pressupostos teóricos}

Possuir uma biblioteca em casa, ou ao menos livros e pais leitores é fundamental, mas não determinante para a formação de leitores. Ter uma biblioteca no bairro ou na comunidade é outro fator essencial para esta formação complexa e socialmente necessária para uma formação crítica e cidadã nestes tempos de ascensão do discurso de ódio autoritário, das mídias sociais e das fake news. A escola também deve representar um papel vital neste processo. Será que ela tem dado conta desta sua função básica? Qual papel ela tem desempenhado nesse processo?

Neste sentido, Teresa Colomer define a "escola como instituição que outorga um sentido específico à leitura de obras" (2007, p. 11). Segundo ela, os livros são os melhores colaboradores dos professores na educação leitora e literária dos alunos, de modo que "a leitura de livros é o ponto de intersecção entre leitura, literatura infantil e juvenil e ensino de literatura" (2007, p. 9), constituindo uma ponte entre a prática docente e as teorias que podem explicá-la e sustentá-la.

Uma das motivações deste artigo é oriunda da observação de Colomer de que "o objetivo de formar o leitor não tem obtido o êxito esperado" (2007, p. 102), acarretando em que conseguir uma população altamente alfabetizada talvez seja um desafio sem precedentes na história da humanidade, pois possivelmente a sociedade já não veja de maneira tão clara que seja necessário certo tipo de alfabetização, uma vez que existem outros meios, como os audiovisuais, que cumprem funções que antes pertenciam à literatura, como o consumo de ficção. Para dar conta desses novos desafios, é preciso concordar com Colomer de que "andar entre livros é a condição essencial da educação literária das novas gerações" (2007, p. 197). 
Para falar de formação de leitores, é preciso definir qual tipo de literatura se deseja estudar na escola, já que existem infindáveis definições que interferem no modo de entendê-la e estudá-la, e o que se entende por leitura. Colomer define três tipos de literaturas escolares. A literatura como um jogo de regras, já que "uma grande parte do aprendizado literário das crianças se baseia na consciência progressiva das convenções que modelam as obras e que guiam nossa leitura" (2007, p. 187). A literatura como debate moral, uma vez que "as crianças têm o direito de saber o que a literatura nos fala" (2007, p. 193). Há também a literatura como variação interpretativa, pois "o jogo de interpretações é uma constatação que faz parte do aprendizado do contraste de leitura. Combate a ideia inicial de que uma obra tem apenas uma significação, sempre e para todo o mundo" já que "a literatura não esgota nunca a sua mensagem" (2007, p. 193).

Também Antonio Candido, em O direito à literatura (1995) e em A literatura e a formação do homem (1972), divide a literatura em três pilares principais: como forma de conhecimento, uma criação autônoma de estrutura e significado e como forma de expressão de indivíduos e de grupos. 0 tipo de conhecimento a ser estudado na escola deve ser libertário, democrático e cidadão, ainda mais nos tempos atuais de acirramento e emersão de discursos autoritários. A literatura estudada no espaço escolar deve permitir a expressão autônoma dos estudantes, individualmente e em grupo, de modo a interpretar de forma crítica e criativa sua estrutura autônoma e seus significados.

Quanto à definição de leitura, Colomer delineia duas dimensões: a leitura compreensiva, aquela que se limita a explorar os elementos internos do enunciado, os sentidos denotados; e a leitura interpretativa, aquela que utiliza conhecimentos externos para suscitar significados implícitos, segundo sentidos ou símbolos que os leitores fazem emergir do texto. Ambas são alvo do ensino escolar, que, porém, visa o trajeto da primeira para a segunda, naquilo que os OCNs chamariam de arco do leitor vítima, "mais interessado em o que o texto conta, uma vítima do enunciado", ao leitor crítico, "mais interessado em como o texto narra, também interessado no modo de enunciação" (2006, p. 68). Paulo Freire defende explicitamente o segundo entendimento de leitura, interpretativa para Colomer e crítica, para os OCNs.

Há que se concordar também com Paulo Freire de que o ato de ler e escrever são "indicotomizáveis" e que mais importante do que simplesmente ler a palavra é ler a "palavramundo", o que só pode se dar pela dodiscência. Segundo Freire, "a leitura da palavra, da frase, da sentença, jamais significou uma ruptura com a 'leitura' do mundo. Com ela, a leitura da palavra foi a leitura da 'palavramundo'”(1989, p. 11). Em A importância do ato de ler, ele delineia bem o caminho que leva da leitura da palavra para a de mundo:

Refiro-me a que a leitura do mundo precede sempre a leitura da palavra e a leitura desta implica a continuidade da leitura daquele. Na proposta a que me referi acima, este movimento do mundo à palavra e da palavra ao mundo está sempre presente. Movimento em que a palavra dita flui do mundo mesmo através da leitura que dele 
fazemos. De alguma maneira, porém, podemos ir mais longe e dizer que a leitura da palavra não é apenas precedida pela leitura do mundo, mas por uma certa forma de "escrevê-lo" ou de "reescrevê-lo", quer dizer, de transformá-lo através de nossa prática consciente (1989, p. 13) .

Paulo Freire sempre se colocou contra uma leitura meramente mecânica ou, pior ainda, para extração de classes gramaticais, meramente por exercício de nomenclatura vazia. O estudo gramatical deve ser feito para fornecer instrumentos interpretativos aos estudantes, de maneira dinâmica e viva, crítica e criativa. Por ser favorável à leitura profunda, defendia a leitura dos clássicos, que se encontra em crise nos dias de hoje, como veremos ao longo da análise dos dados fornecidos pelos estudantes do Ensino Fundamental Il e Médio do CAp UERJ.

Por isso, ele entendia que "a importância do ato de ler [] implica sempre percepção crítica, interpretação e 're-escrita' do lido" (1998, p. 14). Assim, o educador jamais será um agente neutro, o que não significa também que seja um manipulador. Todo ato educativo é um ato político, de modo que é necessário ter clareza a favor de que e de quem, portanto, contra que e quem fazemos a educação e desenvolvemos a atividade política, não sendo possível pensar a educação sem que se esteja atento à questão do poder, para que a escola não se torne um aparelho ideológico de Estado, como analisou Louis Althusser.

Althusser entendia que "a escola constitui o aparelho ideológico de Estado dominante e desempenha papel determinante na reprodução das relações de produção" (1985, p. 34), de modo que o processo de seleção escolar prevê cada massa que entorna do aparelho escolar com a "ideologia que convém" ao seu papel na sociedade de classes. Deste modo, ele entendia que não existe prática senão de e sob uma ideologia e não existe ideologia senão através do sujeito e para sujeitos, sendo que "o sujeito é o resultado de uma estratégia de poder que vigia e ordena os corpos através do aprisionamento e da domesticação das almas" (1985, p. 51). Com isso, nos cabe perguntar qual papel ideológico a formação de leitores tem exercido no CAp UERJ atualmente, o de domesticador, ou de estímulo ao sujeito autônomo, crítico e criativo. A escola tem estimulado ou desestimulado a formação de leitores?

\section{Metodologia}

Esta pesquisa foi realizada a partir de produção textual de estudantes de 6ㅇ e 9ㅇa anos do Ensino Fundamental, 1ํ e 2o anos do Médio do Instituto de Aplicação Fernando Rodrigues da Silveira (CAp UERJ), denominada autobiografia literária. Desse modo, abrange-se o ano inicial e final do Ensino Fundamental, dando uma ideia da trajetória percorrida por estes educandos, bem como os dois primeiros anos do Ensino Médio, o que permite uma visão de permeio tanto da experiência leitora dos 
discentes no Ensino Médio quanto de um paralelo entre esta experiência mais recente, sob alterações significativas no cotidiano escolar dos alunos (em especial no tocante à grade curricular, especialmente a respeito da nova segmentação disciplinar), e a pregressa, no Ensino Fundamental, em que pese nos depoimentos desses alunos do Médio a importância desse período anterior de formação escolar. 0 3o ano do E.M. foi excluído da pesquisa por se tratar de ano de escolaridade preparatório para a entrada no Ensino Superior, o que os consome desde o início do ano letivo.

Foi dada preferência por partir de poucas coordenadas, especificamente: quando comecei a ler? O que (não) gosto de ler? Em qual situação gosto de ler? Qual gênero literário ou textual mais gosto de ler? Qual livro mais me marcou? A intenção era fazer os alunos escreverem sobre sua experiência leitora com base em poucos dados com a certeza de que apareceriam muito mais informações do que as solicitadas, o que efetivamente ocorreu. A partir desses elementos será feita uma análise de dados que demonstre como vem se dando a formação leitora dos educandos do CAp UERJ.

O relato espontâneo dos estudantes se faz importante na medida em que nas produções textuais escolares muitas vezes eles escrevem tentando agradar o professor, que é o seu natural avaliador. Tirar a tensão desse tipo de produção faz com que os dados se tornem mais confiáveis, fidedignos e, consequentemente, a pesquisa mais profícua.

Para promover a análise de dados e chegar a algumas destas respostas será necessário confrontar as teses de Althusser sobre a escola como aparelho ideológico de Estado dominante na modernidade com a de leitura crítica, criativa e libertadora de Paulo Freire, numa reflexão potente sobre o papel do CAp UERJ na formação democrática de leitores críticos, por andarem livres entre livros, como defende Teresa Colomer. A tese de Raquel de Souza sobre os critérios de avaliação do gosto leitor dos estudantes também será um mecanismo fundamental desta análise. Portanto, a pesquisa bibliográfica constitui elemento metodológico fundamental para se chegar aos resultados analíticos e críticos aqui almejados.

Contudo, a principal metodologia, sem dúvida, é o materialismo dialético, analisando os dados a partir da perspectiva da luta de classes e da história escolar de nosso país, sobretudo desde a década de 70, quando se começa a investir na universalização do ensino. Qual ensino foi universalizado? Para quem? Atendendo a quais interesses? Analisar quais classes estão envolvidas no processo pedagógico e em qual jogo ideológico é lapidar para delinearmos qual tipo de formação leitora se vem praticando em nossa instituição. Uma perspectiva libertária se faz fundamental para entendermos como esse processo se dá, seus resultados e os possíveis aprimoramentos possíveis e pertinentes para o afloramento de uma consciência leitora crítica, cidadã e democrática.

\section{Análise de dados}


O 60 ano do Ensino Fundamental do CAp UERJ apontou dados interessantes. Quase 50\% indicou a mãe como a principal incentivadora pelas primeiras leituras e por sua formação leitora, seja lendo de noite, seja ensinando a ler, por ser professora ou de outros modos. Se agregarmos a esses dados aqueles que atribuíram à família, livros em casa, ao pai, prima, tia, avó, segundo membro familiar mais citado, a família é a principal incentivadora da formação de leitores neste segmento escolar.

O segundo principal responsável por esta formação foi a escola e a creche, curiosamente por meio da obrigação de leitura. Há um debate teórico na atualidade sobre a leitura obrigatória na escola, com argumento a favor e contra. Não cabe aqui fazer este juízo de valor, mas apenas retratar os dados fornecidos pelos próprios estudantes. Contudo, vale notar que a leitura obrigatória tem exercido seu papel, ao menos segundo estes relatos, mas talvez não baste, pois é preciso ir além e formar leitores regulares e perenes.

Quanto à primeira obra lida, houve uma variação muito grande, sendo citados Lobo Maurinho, de Gustavo Luiz e Mig, Um passeio pela África, de Alberto da Costa e Silva, A ilha perdida, de Maria José Dupré, da famosa série Vaga-Lume, a autora Ruth Rocha, mas, sem dúvida, o primeiro texto lido pelos jovens costuma ser o gibi da turma da Mônica, de Maurício de Sousa, que também aparece entre as obras preferidas. Os livros que mais estimularam a sequência de formação leitora foram: Diário de um banana, o gibi da turma da Mônica, a escritora Ruth Rocha e a literatura infantil.

Nesta faixa-etária, o texto preferido, de longe, é o Diário de um Banana, de Jeff Kinney, citado por quase metade dos estudantes. $O$ segundo mais citado, com menos da metade de incidências, foi Percy Jackson, de Rick Riordan, junto com vários livros da série Harry Potter, de J. K. Rowling, seguidos por $A$ bela e a fera, fábula clássica da literatura infantil, por Ruth Rocha e Thalita Rebouças, sobretudo a série Fala sério, e por Paula Pimenta, com Minha vida fora de série e Fazendo meu filme. Também foram citados Ponte para Terabítia, de Katherine Paterson, Diários de Pilar, de Flávia Lins e Silva, Meus 15 anos, de Luiza Trigo e Irene Freitas, Histórias para ninar garotas rebeldes, de Elena Favilli e Francesca Cavallo, Querido diário otário, de Jim Benton, Ziraldo, Rebeldes, de Bernard Cornwell, Monteiro Lobato e Divergente, de Veronica Roth.

Embora o estudo de fábulas faça parte do conteúdo estudado do 6ำ ano do Fundamental do CAp UERJ, apenas uma obra do gênero foi citada e por pouco mais de $10 \%$ dos estudantes, de modo que podemos concluir que, por esta amostragem, a escola não vem influenciando tanto o gosto dos estudantes. Nenhum mito africano ou indígena foi citado, apesar de também fazerem parte do plano de aula desse ano escolar.

Os gêneros literários preferidos foram $\mathrm{HQ}$, sobretudo o gibi da turma da Mônica, literatura infanto-juvenil, seguidos por fábula, aventura, ação, comédia, livros sobre guerras. Também foram 
citadas obras sobre desastres naturais, relato de sobreviventes, literatura, ciência, mangá, ficção científica, terror, romance, poesia, suspense, fantasia e Ruth Rocha. Quanto à preferência por quadrinhos e outras formas que se ligam à mass media podemos citar a tese de Raquel de Souza:

Desde a década de 50 o mercado brasileiro tem sido invadido por todo tipo de produto norte-americano, incluindo aí o próprio american way of life impresso nos programas de TV, nas revistas semanais de informação e reportagem e também nos quadrinhos. É nesta década que uma sensibilidade adolescente começa a se infiltrar na cultura de massa, segundo Edgar Morin (2007), a partir de uma ética do lazer e uma estética da juventude. A literatura é apenas mais um dos terrenos colonizados pela imperiosa indústria cultural dos Estados Unidos (2015, p. 143).

Foram citados como fatores que levam à preferência por estes gêneros ter visto filmes sobre o assunto, a curiosidade, o mistério, o entretenimento e a oposição ao machismo. Os motivos que levam a gostar de ler também são bastante variados. Os principais são: ter visto filme sobre o livro, diversão e conhecimento. Vale ressaltar o entendimento deste pouco mais de $10 \%$ dos estudantes que relaciona a literatura ao conhecimento e à aprendizagem, já que se trata de uma percepção mais especializada e apurada, diferente do seu entendimento enquanto entretenimento que já faz parte do senso comum por meio da cultura de massa. Outras causas consistem em viver a experiência proporcionada pelo livro, ele ser engraçado, legal, o que entra na seara do entretenimento, ser mágico, além do enredo, identificação com os personagens, expectativa pelo que vai acontecer, o que se coaduna com um enredo de causa e efeito, o mistério, a curiosidade despertada pela obra, a oposição ao machismo, o tema ou abordar mais temas diferentes.

Os dados denotados pelos educandos parecem coincidir com os critérios de avaliação dos adolescentes apontados pela tese de Raquel de Souza: 1- o entretenimento, "parece, portanto, que o entretenimento, a distração e o humor são valores importantes, o que se confirma com a análise quantitativa das preferências centrada no polo da indústria cultural” (2015, p. 156); 2-identificação e projeção, reconhecimento de uma semelhança, desejo de ser ou agir de forma semelhante; 3realismo, promover o efeito de real; 4- conhecimento, aprendizado; 5- resposta emotiva, aquela que faça com que se emocionem; 6- enredamento na trama, intriga como elemento central da narrativa; 7- imersão no mundo fabulado; 8- rapidez, fluidez e simplicidade. Critérios que a levam a uma importante reflexão final: "leitores formados preponderantemente pelo polo da literatura de entretenimento não são necessariamente 'incapazes' de apreciar o que é diferente ou de entender textos mais complexos" (2015, p. 389).

Surpreendentemente, a situação em que estudantes declararam gostar de ler foi na condução ou em viagem, mas também quando não têm nada para fazer, ou seja, nas horas vagas, no ócio, o que pode nos levar a entender que eles relacionam a leitura a um passatempo. Se considerarmos a preferência pela leitura no quarto, na sala de estar, antes de dormir, quando está sem sono e em casa em uma mesma categoria, o lar é o lugar preferencial para a realização da leitura, provavelmente pela tranquilidade que permite uma maior concentração, o que nos permite inferir que a maioria dos alunos 
ligam a leitura à atenção e concentração, mais do que a passatempo e entretenimento. Os educandos também alegaram gostar de ler de tarde, de noite, em noites chuvosas, no frio e quando estão entediados. Poucos gostam de ler na escola e na biblioteca. Se considerarmos que esse relato diz respeito à biblioteca da escola, então pouco mais de $10 \%$ gosta de ler na escola, ficando apenas atrás do lar e da condução. De qualquer forma, a escola não consiste no principal lugar de leitura desses jovens.

Vale ressaltar que $20 \%$ dos educandos declararam não gostar de ler. Em uma produção textual para um professor de português/literatura, esse dado é muito relevante, pois muitos estudantes evitam fazer esse tipo de revelação com receio de o docente não gostar, o que nos leva a crer que o número de alunos que creem não gostar de ler seja ainda maior. Os principais motivos declarados para não gostar de ler é a falta de paciência, o tamanho do livro e a preguiça, ou seja, todos relataram o mesmo motivo apenas utilizando palavras diferentes.

Em relação ao 9o ano do Fundamental, o principal motivo para o começo da leitura é o incentivo da família, junto com o incentivo da mãe, seguido de perto pelo incentivo dos pais e dos professores, estes dois com a mesma incidência de citação. Considerando que a categoria "pais" inclui a mãe, elas são, de longe, as maiores incentivadoras à formação leitora dos filhos, assim como já havia aparecido no 60 ano. $O$ interessante é que agora os professores aparecem com força entre os principais formadores de leitores. A escola também aparece expressivamente, tendo metade declarado o incentivo da escola e a outra, ser obrigada pela escola. De qualquer forma, a leitura obrigatória volta a se mostrar relevante para a formação leitora, com qual prazo de validade já é outra história, o que deve ser debatido com profundidade. Outro fator escolar que apareceu com peso foi a roda de leitura promovida pelo Capinho (Ensino Fundamental I do CAp UERJ). Trataremos da importância específica da roda de leitura em outro artigo.

Apenas um aluno declarou ter sido incentivado pelo pai, um pela avó e três pela tia. O fato é que a família aparece como principal agente motivador, sobretudo os membros do gênero feminino. Outros motivadores citados foram, primeiramente, a BIENAL, seguida pelos quadrinhos, pelo livro Diário de um banana, pela filha de uma professora e apenas uma aluna declarou ter se sentido incentivada pela Bíblia, o que numa cidade de ascensão evangélica, muitas vezes extremista, como o Rio, não deixa de constituir um dado curioso.

A primeira obra lida pela maioria segue sendo os gibis, muito à frente da segunda mais lida, sendo o gibi da turma da Mônica o mais citado. O Diário de um banana também aparece com relevância, assim como Harry Potter, a literatura infantil e livros de História. Também foram citados o folclore, a mitologia, a revista Recreio, revistas infantis, O pequeno príncipe e a Bíblia.

Entre as obras favoritas há uma variedade enorme, mas, mais uma vez, a mais citada foi a turma da Mônica. Com uma citação a menos, aparece a série Percy Jackon e com uma a menos Harry 
Potter, seguida por Paula Pimenta e pela HQ do Watchmen, o que comprova a predileção dessa faixa etária por $\mathrm{HQ}$, assim como havíamos detectado no 60 ano. A literatura infanto-juvenil aparece com força assim como obras de aventura com imaginário mitológico e medieval. Outras HQs também foram citadas, da Marvel, do Mickey e do Batman. A autora E. L. James também teve destaque com as obras "Cinquenta tons de cinza" e "Cinquenta tons de liberdade". Na Espanha, também Colomer nota a preferência dessa faixa etária por livros fantásticos e temas atuais, com repúdio a outros gêneros. Ela também afere que "os contos nos quais os filmes de Walt Disney se baseiam continuam sendo os preferidos" (2007, p. 136).

Também foram citados: Extraordinário, de R. J. Palacio; A culpa é das estrelas, de John Green; As crônicas de Nárnia, de C. S. Lewis; Prisioneiros da geografia, de Tim Marshall; O mundo pósocidental, de Oliver Stuenkel e Renato Aguiar; Rayane Leão; contos de fadas; Happer Lee; Se a rua Beale falasse, de James Baldwin; Eu sei por que o pássaro canta na gaiola, de Maya Angelou; A menina que roubava livros, de Markus Zusak; Subindo pelas paredes, de Alice Clayton; Gillian Flynn; O pequeno príncipe, de Saint-Exupéry; Matilda, de Roald Dahl; A cinco passos de você, de Rachael Lippincott, Mikki Daughtry, Tobias laconis e Amanda Moura; Dom Quixote, de Miguel de Cervantes, embora provavelmente se trate de alguma adaptação para a literatura infanto-juvenil; Rupi Kaur e Capitão cueca, de Dav Pilkey.

Quanto ao gênero literário preferido, a surpresa foi grande, pois o mais citado foi romance, por praticamente metade dos estudantes. Embora o conteúdo programático do 9o ano do CAp UERJ inclua o estudo do romance, só esse fator já pode explicar tal gosto? Provavelmente não. Ao citar romance como gênero preferido, certamente os estudantes não estão se referindo a Machado de Assis, Guimarães Rosa ou Clarice Lispector. Os estudantes costumam entender o gênero romance como histórias de amor, ou histórias românticas, o que parece bem apropriado a essa faixa etária e à sua situação hormonal.

O segundo gênero mais citado foi $\mathrm{HQ}$, por mais de um terço da turma. A mistura de imagem e texto parece ainda ser o mais sedutor para os jovens. $O$ imediatismo vigente que leva a querer acabar de ler logo a obra talvez explique em grande parte esse fenômeno também. $O$ terceiro gênero mais citado foi ficção científica, que só teve uma citação no 60 ano. Parece que com o avanço da idade, os jovens começam a se sentir mais atraídos por esse gênero. Com muito menos incidência aparece a fanfic, que não havia aparecido no 60 ano, seguido de perto por aventura, gosto que pode ter sido cunhado pela passagem pelo 7ํano, a Alternative Universe, AU, gênero que parece começar a cair nas graças dos adolescentes, e contos de fadas, provavelmente por influência do 60 ano.

Na mesma proporção, aparece o erótico/pornográfico, seguido por suspense, terror e poesia. Foram citados também gêneros políticos, artísticos, literários, mitologia, notícias, livros baseados em fatos reais, autoajuda e autorreflexivo, crítica social, movimento negro americano, artigos científicos, 
mistério, livros de filmes, literatura juvenil, comédia, ação, magia, Bíblia e revistas infantis. Com a idade, os estudantes parecem começar a se interessar mais por política e temas sociais em geral, o que parece ser uma grande conquista da escola, embora não se possa comprovar ainda que ela seja a responsável por isso, já que estamos vendo que a família é a grande influenciadora do gosto literário e pela formação do leitor.

O motivo da preferência por esses gêneros é extremamente diversificado, abrangendo o político, artístico, literário, ter ido ao teatro, a debate sobre o tema, ter lido ou visto um documentário, fotografia, desenhos, música, gastronomia, emoção e identificação. A situação em que mais gostam de ler envolve a concentração, tendo declarado gostar de ler sozinhos, especificamente concentrados, antes de dormir, em casa, lugares calmos, com silêncio ou escutando música. A esse respeito, Colomer defende "a criação de um espaço de leitura individual na escola pretende[ndo] dar a oportunidade de ler a todos os alunos", uma vez que "a leitura autônoma, continuada, silenciosa, de gratificação imediata e livre escolha, é imprescindível para o desenvolvimento das competências leitoras" (2007, p. 125).

Também foram citados tempo livre, biblioteca, banheiro, tédio, carro, escola, condução, de manhã, na cama, confortável e no frio. De todo modo, o lar é o principal lugar de leitura, muito à frente da escola. É interessante observar como os estudantes são capazes de ligar a leitura à concentração, sem dúvida um fator fundamental para essa capacidade, mas também ao lar e muito pouco à escola, que aparece em igual proporção à condução. Colomer também fala sobre a ponte entre a leitura individual e a coletiva. Para ela, "as crianças que exploram juntas os livros se acostumam depressa a perceber os jogos intertextuais, as estruturas paralelas, as repetições, as linhas de sentido etc. se acham na base do modo de significar da literatura" (2007, p. 145), de modo que

compartilhar a leitura significa socializá-la, ou seja, estabelecer um caminho a partir da recepção individual até a relação de sentido de uma comunidade cultural que a interpreta e avalia. A escola é o contexto de relação onde se constrói essa ponte e se dá às crianças a oportunidade de atravessá-las (2007, p. 147).

A explicação de gostar de ler também é bastante reveladora. A maioria diz gostar de ler para aquisição de conhecimento, um dos principais pilares de toda a literatura. $O$ segundo principal motivo também é base dessa arte, a criatividade, que, se juntarmos à inspiração e imaginação, ficam pouco acima do conhecimento. Outros fatores revelados são aprender sobre a linguagem, o que entra na seara do conhecimento, que mais uma vez empata com a criatividade, o início envolvente, que tem a ver com o enredo, as imagens, investimento em seu futuro, o que também pode se ligar ao conhecimento, dar outro sentido, ser mais detalhado, identificação, entrar no mundo literário, imaginar como seria se fosse real, e apenas um declarou ser o entretenimento.

A esse respeito é necessário mais uma vez reivindicar a percepção apurada de Colomer de que "[se] sabe muito pouco [...] sobre as causas que fazem com que um livro estabeleça contato com seus 
leitores" (2007, p. 136). Em relação aos dados do 60 ano, parece que com o tempo os estudantes começam a ligar mais a literatura ao conhecimento e à imaginação do que ao entretenimento. Talvez isso seja responsabilidade da própria maturidade, mas a escola deve ter alguma parcela nesse aprimoramento do gosto e do entendimento da arte literária. Alguns alunos declararam sua frequência de leitura, dois alegaram ler todo dia; dois, um livro por semana; um, dia sim, dia não; um, mensalmente; um, medianamente e um deseja ler duas vezes por semana.

O que os faz não gostar de ler ou abandonar a leitura também revela bastante sobre nossa formação leitora. Foram mencionados os clássicos e a falta de imagens como o que os faz não gostar de ler. A falta de tempo livre é o principal fator alegado para que eles deixem de ler. Vale lembrar que o CAp UERJ é um colégio de horário integral e que a maioria dos alunos reside longe da escola, onde poucos declaram ser o local favorito para ler, de modo que passam pouco tempo em casa, lugar apontado como o preferido para realizar leitura. Fato ainda mais relevante porque a escola foi o segundo principal fator que os faz deixar de ler. Curiosamente, cabe ressaltar, no caso dos alunos do Ensino Médio, a presença de cinco relatos que apontam a carga horária de estudos, isto é, a exigência acadêmica imposta pelo próprio colégio de aplicação, como fator preponderante para a queda de assiduidade na prática leitora.

Além disso, caso se limite para alunos tanto do Fundamental quanto do Médio, foram citados também a falta de vontade, de interesse, ter enjoado, preferir escrever e problema na visão. Mais uma vez é Colomer quem comenta sobre o repúdio generalizado à leitura durante a adolescência, por considerá-la uma atividade alheia, elitista, ou própria da geração adulta ou sua associação com a fase infantil ou como uma atividade feminina, ou, mais especificamente pela "percepção da literatura como uma mera disciplina escolar ou, ao contrário, como uma atividade optativa incompatível com a imposição de textos ou obrigações leitoras, ou o temor da independência que a leitura dá ao indivíduo" (2007, p. 113).

E quanto ao Ensino Médio? Os depoimentos, relatos, enfim, a perspectiva dos alunos a respeito de sua formação e trajetória enquanto leitores permanece a mesma? Com a passagem dos alunos do Ensino Fundamental para o Ensino Médio, e, também, pela mudança de faixa etária, há modificações dignas de nota? Vejamos.

O corpo de dados, nesse caso, se constitui de textos produzidos por alunos da primeira e da segunda série do Ensino Médio. Os textos atenderam à mesma proposta dirigida aos alunos do Ensino Fundamental. Pediu-se que se escrevesse uma "autobiografia literária".

A partir dos dados relativos aos textos escritos pelos educandos do Ensino Médio, pode-se observar tanto a persistência de alguns indicadores do Ensino Fundamental quanto a presença de novos, a saber: a predileção por novos gêneros literários, embora o romance ainda seja o preferido; a presença mais marcante de uma autoconsciência dos autores dos textos enquanto escritores, 
fenômeno observável tanto pela adoção de filtros discursivos como estratégias para explicar baixa assiduidade na prática de leitura quanto pela autoafirmação dos educandos como produtores de texto, escritores.

Os principais agentes incentivadores da prática leitora são, ainda, a família (pais, irmãos e outros familiares) e a escola (especialmente a roda de leitura). Para cerca de $60 \%$ dos educandos, o principal incentivador é a família, seja pelo incentivo direto, seja pela presença de livros em casa. $\mathrm{Na}$ maioria desses casos, é a mãe a principal incentivadora, ressalva feita a dois relatos: um marcado pela presença afetiva de um irmão; outro, de um episódio, cuja memória da autora do texto marca como momento inaugural de sua trajetória de leitora, de uma visita, na companhia do pai, à Bienal do Livro. Ainda nessa linha, sublinhe-se também um relato, marcado por efetivo investimento estilístico (certo anacronismo de linguagem, marcado pela adoção de um registro demasiado), de um primeiro encontro com o livro pela narrativa da descoberta de um presente surpresa num embrulho com laçarote encontrado em casa. Para cerca de um quinto dos trabalhos, a escola aparece tanto como primeira incentivadora quanto como agente de reforço de hábito contraído no seio familiar; curiosamente, esse é o mesmo número de textos que ressalta a importância da Roda de Leitura do Capinho.

Um último dado importante ainda neste âmbito é a prática da leitura, pelos pais (especialmente a mãe), na beira da cama. Há aqui, nesse conjunto, em quatro relatos, a marcação de uma formação leitora antes da alfabetização. Paulo Freire, em A importância do ato de ler (Freire, 1989, p.9), faz uma aguda e original consideração a respeito da formação leitora quando pontua que antes da alfabetização em um idioma, antes do letramento, o indivíduo é iniciado sorte de letramento, formação para a leitura da "palavramundo"; diz também que esse período da formação leitora, anterior à alfabetização é determinante para toda a trajetória seguinte dos leitores depois de letrados, em sentido estrito. Nesse sentido, a evocação de uma memória afetiva da leitura à beira da cama, do contato com o texto como prática de escuta desponta como traço marcante da trajetória desses leitores. Tangencialmente, um caso que parece confirmar às avessas o que diz Paulo Freire está na presença de um texto, de um aluno do segundo ano do Ensino Médio, que associa a prática de leitura a uma experiência traumática. Nesse relato, diz que sempre sofreu com problemas de visão, mas que, quando ainda no início da trajetória escolar no Ensino Fundamental, não tinha ciência de seu diagnóstico oftalmológico e, portanto, manifestava dificuldades no exercício de leituras cujas causas atribuídas pouco tinham de relação com as razões reais dos percalços.

No caso para a indicação das primeiras obras lidas, os mais citados continuam sendo as Histórias em quadrinhos, especialmente os gibis da série A turma da Mônica. Em quase um terço dos casos, a primeira leitura da qual os autores se lembram é de Histórias em Quadrinhos; além da referida série, em três casos aludiu-se aos mangás, sem que se fizesse menção a um título específico. 
Outros títulos apareceram também com recorrência sem que se pudesse distinguir se foi a primeira leitura, ou somente uma obra que se tenha lido, na trajetória de leitores dos educandos, a saber: seis alusões a E não sobrou nenhum de Agatha Christie, romance policial indicado no sétimo ano do Ensino Fundamental do CAp UERJ, cinco aos já citados Diário de um banana e às séries Percy Jackson e Harry Potter. Outros títulos mencionados foram: A llíada de Homero; Um passeio pela África de Alberto da Costa; Ludi na Revolta da Vacina de Sandroni; Mil léguas submarinas de Júlio Verne; a série Jogos Vorazes; Barbie e o castelo de diamantes; livros da autoria de Paula Pimenta (evocados assim, numa citação, de forma geral, sem que se detalhasse o seu título); a série de livros Fala Sério de Thalita Rebouças; Orgulho e Preconceito de Jane Austen; a série de livros The Bridgertons; $O$ ódio que você semeia de Angie Thomas; Persépolis de Marjane Satrapi; Quarto de despejo: diário de uma favelada de Carolina Maria de Jesus; a obra, assim de forma generalista, de Machado de Assis; Estudo em vermelho de Arthur Conan Doyle (ressalte-se que na mesma redação a que se alude a esse título, evoca-se também, do mesmo autor, $O$ signo dos quatro e As aventuras de Sherlock Holmes); $A$ invenção de Hugo Cabret de Brian Selznick; a série Meu querido diário otário de Jim Benton; A culpa é das estrelas de John Green e A consultora teen de Patrícia Barboza. Em termos gerais, sem que se fizesse indicação imediata a um título, quatro redações apontaram os contos de fada como primeira leitura.

Entre gêneros e subgêneros de preferência, citou-se, com maior frequência, o romance. Além disso, evocou-se: HQs, mangás, fantasia, ficção científica, narrativas de suspense, "romances românticos" (cujo teor são histórias de amor), aventura, artigos de jornal, tweets e postagens de redes sociais e, finalmente, poesia.

Sobre esses últimos gêneros cabe traçar alguns comentários que ganharam relevo pela sua singularidade. No primeiro caso, fale-se da preponderância das redes sociais como influência promotora de desinteresse. Dez relatos pontuaram o quanto as redes sociais são contraproducentes na medida em que absorve a atenção e o tempo que, porventura, pudesse ser dedicado à leitura. Em um caso particular, curiosamente, uma estudante apontava o quanto entende como uma ideia absurda, hoje, por causa da centralidade das redes sociais e mídias digitais, corresponder a um nível alto de concentração que um livro de fôlego. Na contramão, um relato interessante de uma outra estudante que entende que as tecnologias e mídias digitais foram facilitadoras. Nesse mesmo trabalho, aponta ser leitora assídua de jornais digitais. Finalmente, uma última consideração que diz respeito à predileção pelo gênero poesia, que encerra uma conjectura. Além de uma aluna do primeiro ano do Ensino Médio, que ressaltou seu interesse pela poética de Cecília Meireles, ressaltem-se três outros casos de alunas que manifestaram seu interesse pela leitura de poesia (entre as quais, um caso de convergência entre interesse como leitora e afirmação de vocação como poeta). Aqui, a hipótese, opera como traços característicos e, possivelmente, atratores do gênero: a complexidade dos temas e dos jogos de linguagem envolvidos no registro poético, por assim dizer; o traço episódico e 
fragmentário do registro poético, desde os discursos que articula até fatores materiais, como é o caso da mancha gráfica. Talvez, conclui-se, essa relação tenha tanto afinidade com certo amadurecimento etário quanto com a semelhança do registro poético, grosso modo, com a velocidade dos registros de linguagem aos quais esses jovens leitores e leitoras estão expostos nas mídias sociais e em um mundo que parece solicitar e moldar atenções cada vez mais fragmentárias.

\section{Considerações finais}

Segundo relato espontâneo dos estudantes, a escola não constitui o maior formador de leitores nos Ensinos Fundamental e Médio do CAp UERJ. O maior incentivador de leitura na infância são as famílias e possui gênero, o feminino. As mães aparecem como maiores formadoras de leitores dentro das famílias, seguidas, de longe, de outros membros do gênero feminino, como avós, tias e primas. Esporadicamente os pais aparecem neste papel. A escola não aparece nos dados coletados como a principal formadora de leitores e muitas vezes aparece como desestimuladora, o que suscita a questão se o CAp tem exercido o papel de aparelho ideológico de Estado, como delineado por Althusser.

Para ele, todos os aparelhos ideológicos de Estado concorrem para o mesmo resultado: a reprodução das relações de produção, isto é, das relações de exploração capitalista. Deste modo, a escola seria o aparelho ideológico de Estado dominante na modernidade, tendo superado a igreja, dominante da Idade Média. Assim,

a universidade e a escola [...] deixam de ser uma conquista da humanidade a ser preservada das querelas pequeno-burguesas para se tornar não mais instrumento de saber, mas máquinas de sujeição ideológica. 0 que a torna instrumento de subordinação ideológica não são os valores da burguesia e os interesses de seus representantes, mas seu funcionamento ideológico $(1985$, p. 17).

Com isso, "dois setores de uma população preexistem materialmente, mas só se constituem como sujeitos da fé por meio da trama de relações que institui ambos os setores da população como sujeitos sujeitados a um sujeito imaginário" (1985, p. 47).

Em A importância do ato de ler, Paulo Freire parece responder diretamente a essa percepção crítica de Althusser ao observar que

não é possível pensar sequer a educação sem que se pense a questão do poder; se não é possível compreender a educação como uma prática autônoma ou neutra, isto não significa, de modo algum, que a educação sistemática seja uma pura reprodutora da ideologia dominante. As relações entre a educação enquanto subsistema e o sistema maior são relações dinâmicas, contraditórias e não mecânicas. A educação reproduz a ideologia dominante, é certo, mas não faz apenas isto. Nem mesmo em sociedades altamente modernizadas, com classes dominantes realmente competentes e conscientes do papel da educação, ela é apenas reprodutora da ideologia daquelas classes. As contradições que caracterizam a 
sociedade como está sendo penetram a intimidade das instituições pedagógicas em que a educação sistemática se está dando e alteram o seu papel ou o seu esforço reprodutor da ideologia dominante $(1989$, p. 13).

A escola se torna, então, o palco principal da luta de classes, onde seu sistema reproduz as condições de produção da sociedade capitalista, mas também onde se estimula a reflexão crítica, criativa, democrática e libertadora por meio da formação de leitores. Essa formação tem qualidades e defeitos, que têm todas as condições de serem pensados e retificados. Atividades de coletivização da leitura, como a roda de leitura do Capinho, ou a formação de comunidades leitoras, elemento que o CAp UERJ ainda carece de incentivar e elaborar, são fundamentais para uma formação de cidadãos leitores democráticos e críticos, o que não exclui a criação de espaços para leitura individual e de concentração profunda, o que é difícil, mas não impossível, em um espaço escolar físico improvisado e provisório como o do CAp.

A família ser a principal formadora de leitores é um fator positivo para a escola, pois andar entre livros é fundamental, como defende Teresa Colomer, mas a educação sistemática precisa pensar em modos de voltar a ser protagonista deste processo, depois da incorporação das classes subalternas, ocorridas no Brasil a partir da década de 70, o que não necessariamente representa uma integração democrática, pois ela foi realizada no contexto da ditadura, não para democratizar o acesso universal à educação, mas para formar mão de obra qualificada para ser explorada pelo sistema capitalista de produção. Para serem submetidos aos donos dos meios de produção, ainda é preciso construir um processo horizontal de ensino/aprendizagem, com iguais possibilidades cognitivas para todos. Não basta ensinar as classes dominantes para comandar e as dominadas para serem comandadas como mão de obra especializada e barata, é preciso construir uma formação tão universal quanto o acesso. Garantir o acesso universal à escola não basta, é preciso formar leitores críticos a partir de uma educação cidadã e realmente horizontal e democrática.

\section{The reading trainin in CAp UERJ Elementary and High School}

\section{Abstract}

What role has the school been playing in student reading education? What factors encourage reading? How does she start? This article aims to reflect on both these questions and the reading profile of CAp UERJ Elementary and High School students from the data collection through textual production, entitled "literary autobiography", 
in order to collect spontaneous reports from a minimum of coordinates to collect more accurate and reliable data.Thinking about the role of a College of Application in our current society through the perspective of class struggle and ideological state apparatuses is intended to provide an overview of the formation of readers to reflect on the possibility of building a more critical, creative education. and democratic.

Keywords: CAp UERJ. Reader training. Critical reading. Pedagogical policy. Freedom.

Referências

ALTHUSSER, L. Aparelhos ideológicos do Estado. Rio de Janeiro: Graal, 1985.

BRASIL. Orientações curriculares para o Ensino Médio: linguagens, códigos e suas tecnologias (OCN Língua Portuguesa). Brasília: MEC/SEB, 2006.

CANDIDO, A. A literatura e a formação do homem. Ciência e Cultura. São Paulo, v. 24, no 9, p. 803809, 1972.

O direito à literatura. In: Vários escritos. São Paulo: Duas Cidades, 1995.

COLOMER, T. Andar entre livros. São Paulo: Global, 2007.

FREIRE. P. A importância do ato de ler: em três artigos que se completam. São Paulo: Cortez, 1989.

SOUZA, R. C. de S. e. A ficção juvenil brasileira em busca de identidade: a formação do campo leitor. Rio de Janeiro: PPGLV UFRJ, 2015. 